\title{
Research on Implementation of Frontline Public Policy in Current China
}

\author{
Qian Li \\ Party School of the Liaoning Provincial Committee of CPC \\ Shenyang, China 110004
}

\begin{abstract}
-public policy has gradually become the main governing tool of government in China in social transformation period. However, "law is unable to implement by itself", a favorably-prepared public policy requires effective implementation for guarantee the accomplishment of policy objectives. Of which, implementation of frontline public policy, as the "last kilometer" of policy implementation chain, impacts the policy effect; in the meanwhile, the dilemma of implementation of frontline policy has become increasingly prominent. Based on the theory of "field", this article interprets the implementation process of public policy of China from two layers of implementation of frontline policy being as "field" and the external environment of implementation of frontline policy, which provides a new perspective for discussion on the dilemma of implementation of Chinese frontline policy.
\end{abstract} field

Keywords—public policy; implementation of frontline policy;

\section{INTRODUCTION}

CPC put forward pushing on with modernization of the country's governing system and capabilities in the 3rd Plenary Session of 18th CPC Central Committee, and modernization of government governance is its original intention. "The transition from government of domination and economy to serviceoriented government not only greatly changes the government functions but also changes the governing measures. Public policy has gradually become the main governing tool of government". However, "law is unable to implement by itself", a favorably-prepared public policy requires effective implementation for guarantee the accomplishment of policy objectives.

In addition, the development of theory of public policy indicates that, to turn political science to behavioral science instead of merely theoretical science, special attention shall be paid on implementation of policy. The scholars study the policy from different perspectives, which can be concluded as from-top-to-bottom research approach, from-bottom-to-top approach and integrated approach, basically a composition of grandiose narrative nature. At the same time of practice benefiting from the development of these theories, the complexity of practice opens a vaster space for research on implementation of policy. Therefore, confronting the reality of the dilemma of implementation of frontline public policy gradually appearing in the teeth of the storm of public opinion, this article focuses on the implementation of frontline public policy in current China and discusses the "last kilometer" matter of policy implementation from the perspective of "field".

\section{FIELD ANALYSIS ON IMPLEMENTATION OF FRONTLINE POLICY}

Bourdieu thinks that, in well differentiated society, social world composes of many small social worlds which have relative autonomy, and these small worlds are spaces with objective relationship of own logic and inevitability, while these special logic and inevitability are unique. In terms of position in implementation chain, the implementation of frontline policy is at the output end of policy on the connection interface between government and mass, obviously different from the implementation of policy at other levels. The output end of public policy forms a special field with its own characteristics. Hence, on one hand, the structure and custom of the field influence, even decide the consequence of policy implementation. In short, the implementation of frontline policy forms a field in itself, deciding the position and resource of action body, different from other fields in aspects of main body, environment and principles of implementation. On the other hand, the final form of implementation of frontline policy depends on the structures and actors it militates with in the field of public policy process. In other words, the implementation of frontline policy is one of the key factors and links of the implementation field of macroscopic public policy, supplement each other with the implementation processes at other levels. The field of implementation of frontline policy composes of establishment, implementation and evaluation of policy in grandiose narration. Policy process is a complex phenomenon, although each stage is obviously different, they are closely connected with other parts.

\section{A. External Environment Analysis of Implementation Field of Frontline Policy}

In the first place, generally establishment of policy is normal and structured, a few of those in power ranking the top of pyramid decide the objective and direction of policy and issue indicators and orders to implementation department. The influence of policy establishment on policy performance mainly involves in the form, property and degree of definition of policy indication and order and emphasizes on the decision mechanism of policy. Since reform and opening up of China, the governance mode of Chinese government gradually changes to "service-oriented" from "governance-oriented". 
With the exploration and development of government's governance practice, the policy establishment mechanism and conception are all in the process of adjustment and transformation and gradually forms the public decision system of current Chinese government characterized "transition period".

Secondly, Donald S. Van Meter, American scholar, thinks that, "implementation of policy is to continue politics by other means and approaches." Implementation of policy is not merely to mechanically implement the policy and planning; instead, it is influenced by many factors. It is discovered in the observation of the implementation process of policy in China that, the implementation mode is a complex of multiple modes. As described by some scholar, the trebled complex combination of revolution-orientation, bureaucratization and traditional factor makes Chinese socialism have unique characteristics. Therefore, on the basis of bureaucratic mode and mobilization mode of policy implementation, a "familyleader" implementation relative to tradition-orientation still exists. The organization form of family-leader mode is quite simple, so much so that although a certain organization form is established, basically it is superficial, plays a role of "latent rules", and the effect of implementation depends on the private relationship on emotion or interest between the decider and implementer.

Thirdly, Michael Howlett and M. Ramesh divide the policy evaluation into administrative, judicial and political three types. In accordance with the method and main body of evaluation of policy, the effect of evaluation in single form is not quite satisfied; while, although evaluation from different perspectives has different key points, it is able to avoid the strong preference of evaluation in single form. At present, the evaluation method of Chinese public policy pays more attention on administrative and political evaluation, and performance evaluation, as one of the key forms of administrative evaluation, has been recognized by many departments and institutions and played a certain role. In the meanwhile, the requirements for establishment and issuance and implementation of public policy are in line with legal spirit ranging from procedure to content; while, in practice, the judicial evaluation of public policy is relatively scanty. Evaluation of public policy is a systematical project from its principles to methods and main body, etc. However, influenced by the conflict between interest and value of policy evaluation, especially at Chinese local government level, influenced by one-sided concept of political achievement, it leads to a phenomenon of value distortion in policy evaluation made by local government in most cases. The problems of "governmentoriented" economic work and "economized" governmental work existing in local government work results in incomplete and uncompleted evaluations on other aspects.

\section{B. Analysis on Significance of Implementation Field of Frontline Policy}

Firstly, the actors of implementation of frontline policy are diversified and interactive. Inspect the actors of implementation of frontline policy from the perspective of field, we can discover that they are diversified, including the streetlevel bureaucrats implementing policies, superior bureaucrats directly influencing the behavior of street-level bureaucrats, citizens as the target group of policy as well as the external stakeholders, social organization, media and experts, etc. which have influence on the implementation effect of policy. All the actors act upon each other and interplay due to the issue under discussion of policy implementation.

Lipsky, American scholar, who introduces "street-level bureaucrats" into research focus, thinks that, in the face of service objectives, the interpretation of policy objective and use of discretionary power of street-level bureaucrats influences the quality of services they provide and further influences the effect of policy effect, especially the street-bureaucrats directly contacting with public, since they are in the end of policy transmission, possess public resource configuration and have appreciable discretionary power in decision of judgment and punishment and play a role of "policy establishment". By virtue of the two forms of power - "supervision" authority and "action" authority pointed out by Milne the philosopher of law, the street-bureaucrats realize the re-distribution of interest of public policy on the target group. in the implementation process of public policy in current China, in the actual interaction between street-bureaucrats and policy target group, the theoretical right of policy target group in practice is protected and publicized by no means and the supervision right of policy target group in implementation of policy plays a due role by no means, many cases are just symbolically empowered. Due to the non-uniformity of information, complex of situation and contradiction of limitation of administrative discretionary power, the street-level bureaucrats naturally become the strong factors and the policy over while the policy target group becomes the weak factors.

In the implementation of output end of public policy, in addition to main stakeholders, there are external stakeholders; the mass media, as the watchman of the society and supervisor of power, who plays a role of supervision on implementation effect and assistance to the powerless, needs further development due to the microcosmic nature of implementation of output end. The social organization can provide a scale effect for the atomized policy target group to raise their right to speak. However, the current Chinese social organization is weak correspondingly and only strengthening its interaction with common public can it become an important channel of speaking for public.

Secondly, the implementation of frontline policy is up against the pressurized system. One of the characteristics of the normal implementation structure of Chinese public policy described and summarized by scholars at home and abroad is segmentation of trap and block. Bureaucrats, vertical and jurisdictional managements downwards layer by layer from the central government at highest level to basic governments at county and town levels and street sub-district offices; in other words, in terms of top-to-bottom organization form, governments at all levels have the similar structures; in distribution of power, it is vertically-managed centralization and hierarchy that the central or superior government department vertically and directly lead the system. In addition, such centralization and hierarchy are pressure type, showing as "the management method of decomposition of mission quantification and materialized evaluation system for 
completing the indicators issued by superior departments, which is adopted by frontline political organization, in order to realize economic advancement."

"Pressure-type system", as a basic feature of the whole national management bureaucracy system of China, its pressure originates in generalization of bureaucracy, the wand of achievement assessment, organization reformation and market competitiveness. Such intra-organizational pressure can be "transferred" and "amplified" that, the former means the pressure is transferred to the lower level from the superior; the latter means the more pressure the lower level undertakes; the reason is that: firstly, the smaller power the lower level has; secondly, the less members the lower level has.

Thirdly, implementation of frontline policy happens in social structure of "differential pattern". Mr. Fei Xiaotong had profound and instructive opinion which can be summarized by "differential pattern". The street-bureaucrats in "differential pattern" are in modern bureaucracy as well. The bureaucracy requires the organization members acting based on rational rules. The routine business is addressed according to rational rules. "Officer" is "a specialized duty work", the implementation of officer's duty is "carried out according to general, fixed more or less, explained in detail more or less rules which can be learned."

Conflict exists in the role of street-bureaucrats in rational bureaucracy and "differential pattern". In bureaucracy, the action of street-bureaucrats is legal and rational, while in "differential pattern", it is legally passive, even missed; bureaucracy requires professional integrity of streetbureaucrats, however, maintenance of reward and punishment of "differential pattern" and ethical norm is "human relationship", especially street-bureaucrats in rural areas express more obvious. "Clan, as an organization and system, is no longer in existence; however, as a symbolic sign and a concept, it will continue influence the social life of basic level." Hence, street-bureaucrats in "differential pattern" unavoidably conflict with the rational bureaucrats in bureaucracy.

Fourthly, the organization of implementation of frontline policy is characterized duality. Fred W. Riggs, the American scholar, points out in the research on organization of developing countries that, the organization of developing countries is characterized duality, called as "prism organization" by him. Such duality characteristic of Chinese organization is reflected in dual heterogeneity, i.e. the surface structure and potential structure of organization. "Prism organization" is easier influenced by material incentives, as pointed out by Tang Jingping, the Taiwan scholar, "the closer to basic level of political system, the more specific items to be treated and the closer to details of daily life; hence, it more trends to materialism and is harder to win over the support of voter by ideological appeal." Domestic scholars describe the prism mode of basic-level governmental organization with "corporatization" and "demutualization of basic-level government", which not only utilizes the resources of national system, but also escapes from the constraint of system.

\section{REALIZATION OF IMPLEMENTATION OF FRONTLINE POLICY IN FIELD}

The first is interaction between superior bureaucrats and street-bureaucrats. The superior bureaucrats and streetbureaucrats input the public policy into field in forms of delegation - agency, and the superior bureaucrats, as bailor, their objective is to reduce the loss of agent arising from pursuing differential objectives and supervision difficulties, and obtain largest earnings with minimum agent cost. Therefore, the superior bureaucrats will carry out restricting and incentive mechanism on street-bureaucrats to realize the game target; however, in practice, the incentive and control of superior bureaucrats is not enough to offset the administrative discretion of autonomy. In field of frontline implementation, the conflict nature which the public policy is born with decides the inevitability of street-bureaucrats interpreting policy. Lipsky thinks that, the policy maker avoids discussing the conflict in most cases and solves the problems by transferring the conflict to the implementation process of policy; hence, the policy is obscure in description to contain various spaces of interpretations. When the policy conflict extends to implementation stage, the street-bureaucrats need to convert the obscure description into true and specific interpretation aiming at policy target group; while, the policy conflict is given a larger flexible space of policy interpretation. The interpretation of street-bureaucrats is more a conversion of interest than information, because the public policy is the redistribution of interest in nature. The street-bureaucrats conduct individual interpretation for certain purpose based on its degree of awareness and identification of the public policy. We can see that street-bureaucrats have an advantage over superior bureaucrats in the game.

The second is the interaction between street-bureaucrats and policy target group. When carrying out public policy, street-bureaucrat is more a signified state power and governmental authority than an individual existence. Hence, the policy expression of street-bureaucrats in field directly is directly converted as policy will acting on the target group. However, the interpretation understood by street-bureaucrats is not certainly in line with which to be transmitted to target group, and such conversion difference decides the degree restoration of information. Moreover, the information conversion is no single but lives together with policy value. Nevertheless, in the practice of current China, the transmission of policy information and value is basically unidirectional, from top to bottom. In implementation field, theoretically, the target group of policy is interacted with street-bureaucrats; however, in practice, it is almost impossible to realize, the means of target group in the game include their rights of autonomy, participation and supervision, but due to incomplete autonomy, insufficient participation and lack of supervision, an unbalanced and unequal wrestle phenomenon appears in their interaction, the target group is in bad situation. Hence, the street-bureaucrats can influence the conversion degree of policy information and value to target group with their power and authority; in the meanwhile, when the information from target group is converted to the street-bureaucrats, the adverse information is digested by themselves, and the information 
passed to superior bureaucrats through street-bureaucrats is only left with which favorable to them or false information.

\section{CONCLUSION}

Thus it can be seen that, favorable field custom and relationship shall be possessed for implementation of frontline public policy. In terms of implementation of frontline policy as a part of public policy field, corresponding systems and specifications are supposed to be established and completed in the establishment, implementation and evaluation of public policy, providing favorable ecological environment for implementation.

In terms of implementation field of frontline policy per sue, to break implementation dilemma can begin with the following three aspects: the first is to optimize field structure. Reform pressure-type system to transfer the evaluation system of leading cadres fundamentally; deposit traditional culture to form modern administrative atmosphere; complete basic organization to bridge the gap between "should-be" and "actually-be" status. Secondly, street-bureaucrats are supposed to realize the conversion from simple executor to leader. Streetbureaucrats have the leader characteristics as shown in "final authority" of Follett and "acceptance theory of authority" of Barnard, and their understanding and interpretation of policy are accepted by policy target group, reaching policy compliance, so that they become the leader of the field. Such positioning of leader can increase their sense of responsibility and mission, strengthen their attention to society and public and intensify their legal and proper application of power. Thirdly, play the roles of other actors in the field. The policy target group plays the role of supervision; the mass media are supposed to strengthen its channel and ability of information transmission from bottom to top; the social organization is supposed to strengthen their function of expressing the appeals of public interest; the superior leader should possess art of leadership, communicate with other actors when counterbalancing the street-bureaucrats.

\section{REFERENCES}

[1] Yan Qiang. Substance, Characteristics and Content of Analysis on Public Policy [J]. Social Sciences in Nanjiang, 2010(1)

[2] Quoted from Liu Weizhong. Path and Meaning of Research on Implementation of Modern Western Policy [J]. Jianghai Academic Journal, 2006 (3)

[3] Donald S. Van Meter, "The Policy Implementation Process", Administration and Sociaty,6(February) 1975.

[4] Wang Bangzuo, etc. Analysis on Integration of Ruling Party and Society -Take Integration of Communist Party of China and Society of New China as an Example [M]. Shanghai: Shanghai people's publishing house, 2007:89.

[5] Lipsky, Michael.1980. Street-level Bureaucracy: Dilemmas of the Individuah in Public Services, New York: Russell Sage Foundation. 13 , $41^{[-2]}$.

[6] Rong Jingben. Transformation from Pressure-Type System to the System of Democratic Cooperation - Political Restructuring at Township and County Levels [M]. Beijing: Central Compilation Translation Press, 1998:1.

[7] He Yanling. Country and society in urban blocks: investigation in Le Street [M]. Beijing: Social Sciences Academic Press, 2007: 210-212.
[8] [Germany] Max Weber. Economy and Society [M](volume II). Translated by Lin Rongyuan. Beijing: Commercial Press, 1997:281.

[9] Zhang Letian. Farewell to Ideal: Research on People Commune System [M]. Shanghai: Shanghai Orient Publishing Center, 1998.400.

[10] Tang Jingping. Environment Protection and Local Politics: Cognition Investigation on Factors Affecting the Law-Conducting By Environmental Officials in Taibei and Gaoxiong [J]. Taiwan Political Science Review, 2002 (6) 